\title{
IMMUNOHISTOCHEMICAL STUDY OF COX-2 EXPRESSION IN COLORECTAL CARCINOMA
}

\author{
By
Mesbah Fekry Mohamed, Said Abu Al-Khair Mohamed and Naser Abd El-Naby Omar

Department of Pathology, Faculty of Medicine, Al-Azhar University

Corresponding author: Mesbah Fekry Mohamed, E-mail: mesbah.fekry@gmail.com

\begin{abstract}
Background: Colorectal cancer is the third most common cancer worldwide. Several proteins are associated with the development and progression of colorectal cancer including Cox-2 protein. However, it is still controversial whether Cox-2 expression can be regarded as prognostic factor for colorectal cancer patients.

Objective: To study different histopathological patterns of the available cases of colorectal carcinoma, study the immunohistochemical expression of Cox-2 in the available cases of colorectal carcinoma, and correlate the immunohistochemical expression of $\mathrm{Cox}-2$ with tumor type and grade to evaluate their significance in predicting the tumor biologic behavior.
\end{abstract}

Patients and Methods: The study involved thirty cases of colectomy specimens for human colorectal carcinoma that were obtained from Pathology Department, Faculty of Medicine, Al-Azhar University (Assuit), Egypt, during the period from February 2020 up to October 2020.

Results: Cox 2 expression in colorectal carcinoma showed a statistically significant relation with gender and stage of colorectal carcinoma. There was a statistically significant relation between the immunohistochemical expression of Cox 2 and in colorectal carcinoma.

Conclusion: Expression of Cox 2 is usually related to poor outcome and metastasis in colorectal cancer.

Keywords: Cox2, Colorectal carcinoma.

\section{INTRODUCTION}

Colorectal cancer is the third most common cancer worldwide. It is a very common malignant tumor of the digestive tract, with about 1.2 million new cases and 600,000 deaths worldwide each year (Raskov et al., 2014). In Egypt, the relative frequency of colorectal cancer is about 9-12\% with high male predominance 3:1 (Mahfouz et al., 2014). It is the third most common tumor in males after urinary bladder and lymphohemopoietic malignancies, and in females it ranks fifth after breast, lymphohemopoietic, cervical, and urinary bladder cancers. Recently, interest in Egyptian colorectal cancer has been raised when clinical studies revealed a high incidence of the disease among the young Egyptian population (Kazem et al., 2014).

As colorectal cancer has a complicated biologic behavior and is easy to relapse, metastasize, and develop resistance to chemotherapy drugs, the clarification of the mechanisms responsible for the development and progression of colorectal cancer and the development of early and effective diagnostic strategies and reasonable treatment strategies have always been focuses of research in the 
field of colorectal cancer (Sideris and Papagrigoriadis, 2014).

The cyclooxygenase isoenzymes, known as prostaglandin (PG) rate-limiting synthases, catalyze the metabolism of arachidonic acid (AA) to PGs. Finally, a series of biologically active prostaglandins (PGD2, PGE2, PGF2 $\alpha$, and PGI2) and thromboxane A2 (TXA2) are formed. There are three isoforms of the enzyme that have been identified: Cox-1, Cox-2, and Cox-3 (Liu et al., 2015).

Cox-2 is an inducible enzyme and is associated with inflammatory diseases and carcinogenesis (Liu et al., 2015). The Cox-2 enzyme is encoded by the gene located on chromosome 1 at q31.1 (Perisa et al., 2017). It is constitutively overexpressed and to have an oncogenic effect in a variety of cancers, including colorectal cancer. In colorectal cancer, cyclooxygenase-2 (Cox-2) is overexpressed in the tumor tissue compared to the normal colonic mucosa (Lim et al., 2010).

Cyclooxygenase- 2 (COX-2) derived PGE2 is the most abundant prostanoids found in CRC tissue, and it has been demonstrated to promote colon carcinogenesis. Correlations between the expression of COX-2 with tumor growth and distant metastasis have become an issue; thus, attention has been paid to COX-2 expression in CRC (Wang and Dubois 2010).

The aim of this work was to study different histopathological patterns of the available cases of colorectal carcinoma, study the immunohistochemical expression of $\operatorname{Cox} 2$ in the available cases of colorectal carcinoma and correlate the immunohistochemical expression of Cox 2 with tumor type and grade to evaluate their significance in predicting the tumor biologic behavior.

\section{PATIENTS AND METHODS}

The study involved thirty cases of colectomy specimens for human colorectal carcinoma that were obtained from Pathology Department Faculty of Medicine, Al-Azhar University (Assuit), Egypt, during the period from February 2020 up to October 2020.

The study was a retrospective study. Samples were analyzed using immunohistochemistry for COX-2 and its expression intensity in $30 \mathrm{CRC}$ patients.

Inclusion criteria: Patients of both sexes willing for procedure of age ranged from 43 to 74 years old.

A total of 30 archival sample specimens of CRC patients, age ranged from 43 to 74 years, including 17 males and 13 females, were studied for the expression of COX-2 by immunohistochemistry and its intensity to analyze the correlation between the expression of this proteins and their correlation with the clinico-morphological parameters, clinicopathologic parameters, staging, grading, lymph node and location.

Pre-histopathalogical examination: Gross examination of each specimen was done to confirm its site, maximun gross diameter, infiltrating depth in the colon, its shape whether fungating, and ulcerating or annular. Sections were taken from the tumor avoiding the areas of hemorrhages and necrosis. The state of lymph node metastasis was obtained from the pathology report of each case. 
Sections were fixed in $10 \%$ buffered formalin, dehydrated, cleared and embedded in paraffin wax according to routine processing procedures.

Histopathological examination: Two sections $(4 \mu$ thick) were then prepared to be stained with Hematoxylin and Eosin for histopathologic examination and immunohistochemical staining. The slides were re-evaluated, graded and staged according the WHO Histologic classification of colorectal tumors and Duke's staging. One paraffin block best represented the tumor tissue was selected in all the cases (Hamilton et al., 2011). The primary antibody used was cox-2, a ready to use rabbit polyclonal antibody, with a predicted molecular weight of 70 kDa. (Kit no. RB9072R7, Thermo Fisher Scientific, USA). Isotype: IgG. Cellular localization: cytoplasmic.

Immunohistochemistry: The tissue blocks were cut, deparaffinized, rehydrated,rinsed in phosphate buffered saline and then stained by the avidin biotin complex (ABC) according to the method of HSU and co-workers.

Sectioning/ mounting: Tissue sections were cut at 3-5 micrometers, then mounted on positive charged, adhesive slides, dried at 60-70 $\mathrm{C}$ for 1-2 hours (in the oven), then cooled to room temperature.

Deparaffinization/ Rehydration: The slides were de-waxed in xylene for 3 times 5 minutes each, were hydrated in $100 \%, 95 \%, 80 \%$ ethanol for 3 minutes each and immersed in tap water for 5 minutes.

Endogenous peroxide blocking: Slides were immersed in $3 \%$ hydrogen peroxide solution for 10 minutes, then washed in PBS for $2 \times 3$ minutes.

Pretreatment/ Antigen retrieval: Slides were placed in plastic jar filled with citrate $\mathrm{PH}$ 6. They were placed in microwave for 10 minutes and heated to near boiling, then allowed to cool at room temperature for at least 20 minutes before proceeding. Then rinsed in PBS $3 \times 1$ minute before proceeding.

Primary antibody: The slides were put in wet chamber, two drops of cox-2 antibody were added on each slide to cover the entire tissue section. They were incubated for 32 minutes at $37 \mathrm{C}$. Then washed in PBS for $3 \times 3$ minutes.

Secondary antibody (LINK): Tissue was covered with 2 drops of ultra-vision biotinylated goat anti-polyvalent secondary antibody and incubated at room temperature for 10 minutes, then washed in PBS for $3 \times 3$ minutes.

\section{Streptavidin/ peroxidase (LABEL):} Drops of streptavidin peroxidase were added to cover section and incubated at room temperature for 10 minutes, then washed in PBS for $3 \times 3$ minutes.

Substrate/ chromogen: Slides were placed in hematoxylin bath for 1 minute, then washed in water bath 7-8 times and tap water for 5 minutes.

Coverslipping: Sections were dehydrated through $80 \%, 90 \%, 100 \%, 100 \%$ alcohol and in xylene for $3 \times 1$ minute, then few drops of DPX were added and covered by coverslip and allowed to dry for few minutes.

\section{Final analysis:}

All sections were examined for the grade of CRC: I, II, or III (including III, 
IV for simplicity). The staging of carcinomas was done according to Dukes' classifications and presence or absence of vascular and perineural invasion by the tumor. Positive immunoreactivity to COX-2 appeared brown cytoplasmic staining to tumor cells and not to the normal mucosal cells. The entire tissue section was scanned to assign the scores. The staining intensity was scored as 0 (negative), 1 (weak), 2 (medium), and 3 (strong). Staining intensity was scored as follows: 1 = faintly yellow; 2 = brownish yellow; 3 = brown.

\section{Statistical analysis:}

Data were analyzed using Statistical Package for the Social Science (SPSS) version 24. Quantitative data were expressed as mean \pm standard deviation (SD). Qualitative data were expressed as frequency and percentage. Independentsamples t-test of significance: was used when comparing between two means (for normally distributed data.( Chi-square test: was used when comparing between data. T- test is not suitable to compare all the graph highlighted variables in table because data use non parametric use another test, e.g. Man-Whitney test. P value $<0.05$ was considered significant. 


\section{RESULTS}

The current work included 30 cases primarily diagnosed as colorectal carcinomas.

The mean age of all studied patients was $58.8 \pm 11.5$ years with minimum age of 43 years and maximum age of 74 years. There were 13 patients $(43.3 \%)<50$ years and 17 patients $(56.7 \%)>50$ years in the studied patients. As regards sex, there were 17 males $(56.7 \%)$ and 13 females $(43.3 \%)$ in the studied patients.

As regards diagnosis it was adenocarcinoma in 20 patients $(66.7 \%)$, mucinous carcinoma in 7 patients $(23.3 \%)$ and adenocarcinoma + mucoid component in 3 patients $(10 \%)$. It was stage $I$ in 6 patients (20\%), Stage II in 13 patients
(43.3\%) and stage III in 11 patients $(36.7 \%)$. It was poorly differentiated in 7 patients (23.3\%), moderately differentiated in 20 patients $(66.7 \%)$ and well differentiated in 3 patients $(10 \%)$. Lymph node (LN) was positive in 11 patients $(36.7 \%)$ and negative in 19 patients $(63.3 \%)$. It was proximal in 17 patients $(56.7 \%)$ and distal in 13 patients (43.3\%).

COX-2 expression was positive in 23 patients $(76.7 \%)$ and negative in 7 patients (23.3\%). COX-2 expression intensity was weak in 4 patients $(17.4 \%)$, moderate in 10 patients $(43.5 \%)$ and strong in 9 patients (39.1\%) (Table 1).

Table (1): Description of age, sex, tumor characters and COX-2 expression in all studied patients

\begin{tabular}{|c|c|c|c|}
\hline \multicolumn{2}{|r|}{ Parameters } & \multicolumn{2}{|c|}{$\begin{array}{l}\text { Studied patients } \\
\quad(\mathbf{N}=\mathbf{3 0})\end{array}$} \\
\hline \multirow{3}{*}{ Age (years) } & Mean \pm SD & \multicolumn{2}{|c|}{$58.8 \pm 11.5$} \\
\hline & Min - Max & \multicolumn{2}{|c|}{$43-74$} \\
\hline & & $\mathbf{N}$ & $\%$ \\
\hline \multirow{2}{*}{ Age categories } & $<50$ years & 13 & $43.3 \%$ \\
\hline & $>50$ years & 17 & $56.7 \%$ \\
\hline \multirow{2}{*}{ Sex } & Males & 17 & $56.7 \%$ \\
\hline & Females & 13 & $43.3 \%$ \\
\hline \multirow{3}{*}{ Diagnosis } & Adenocarcinoma & 20 & $66.7 \%$ \\
\hline & Mucinous carcinoma & 7 & $23.3 \%$ \\
\hline & Adenocarcinoma + mucoid component & 3 & $10 \%$ \\
\hline \multirow{3}{*}{ Staging } & Stage I & 6 & $20 \%$ \\
\hline & Stage II & 13 & $43.3 \%$ \\
\hline & Stage III & 11 & $36.7 \%$ \\
\hline \multirow{3}{*}{ Grading } & Poorly differentiated & 7 & $23.3 \%$ \\
\hline & Moderately differentiated & 20 & $66.7 \%$ \\
\hline & Well differentiated & 3 & $10 \%$ \\
\hline \multirow{2}{*}{ Lymph node } & Negative & 19 & $63.3 \%$ \\
\hline & Positive & 11 & $36.7 \%$ \\
\hline \multirow{2}{*}{ Location } & Proximal & 17 & $56.7 \%$ \\
\hline & Distal & 13 & $43.3 \%$ \\
\hline \multirow{2}{*}{ COX-2 expression } & Negative & 7 & $23.3 \%$ \\
\hline & Positive & 23 & $76.7 \%$ \\
\hline \multirow{3}{*}{$\begin{array}{l}\text { COX-2 expression } \\
\text { intensity }\end{array}$} & Weak & 4 & $13.3 \%$ \\
\hline & Moderate & 10 & $33.3 \%$ \\
\hline & Strong & 9 & $30 \%$ \\
\hline
\end{tabular}


There were no statistical significant ( $\mathrm{p}$ value $>0.05$ ) correlations between COX-2 expression intensity, age, diagnosis, grading, LN, and location in studied patients. There were statistical significant (p-value $<0.001)$ correlations between COX-2 expression intensity and sex and staging of studied patients. It was higher in females $(28.7 \pm 10.2)$ than males $(13.2$ \pm 2.3 ) (Table 2).

Table (2): Correlation between COX2 expression intensity and age, sex, diagnosis, staging, grading and location

\begin{tabular}{|c|c|c|c|c|c|}
\hline \multicolumn{5}{|c|}{$\begin{array}{ll}\text { COrameters } & \text { COX-2 expression intensity } \\
\end{array}$} & \multirow{3}{*}{$\begin{array}{c}\text { P-value } \\
0.136\end{array}$} \\
\hline \multirow{2}{*}{ Age } & $<50$ years & 13 & $43.3 \%$ & $21.2 \pm 8.15$ & \\
\hline & $>50$ years & 17 & $56.7 \%$ & $17.3 \pm 5.8$ & \\
\hline \multirow{2}{*}{ Sex } & Male & 17 & $56.7 \%$ & $13.2 \pm 2.3$ & \multirow{2}{*}{$<0.001$} \\
\hline & Female & 13 & $43.3 \%$ & $28.7 \pm 10.2$ & \\
\hline \multirow{2}{*}{ Diagnosis } & Adenocarcinoma & 20 & $66.7 \%$ & $20.4 \pm 6.6$ & \multirow{2}{*}{0.099} \\
\hline & Other & 10 & $33.3 \%$ & $16.3 \pm 5.3$ & \\
\hline \multirow{2}{*}{ Staging } & I + II & 19 & $63.3 \%$ & $17.3 \pm 2.3$ & \multirow{2}{*}{0.004} \\
\hline & III & 11 & $36.7 \%$ & $21.3 \pm 4.6$ & \\
\hline \multirow{2}{*}{ Grading } & Poor & 7 & $23.3 \%$ & $28.3 \pm 5.4$ & \multirow{2}{*}{0.105} \\
\hline & Well + Moderate & 23 & $76.7 \%$ & $24.9 \pm 4.5$ & \\
\hline \multirow{2}{*}{$\begin{array}{c}\text { Lymph } \\
\text { nodes }\end{array}$} & Negative & 19 & $63.3 \%$ & $22.4 \pm 5.1$ & \multirow{2}{*}{0.089} \\
\hline & Positive & 11 & $36.7 \%$ & $18.9 \pm 6.5$ & \\
\hline \multirow{2}{*}{ Location } & Proximal & 17 & $56.7 \%$ & $21.1 \pm 3.1$ & \multirow{2}{*}{0.071} \\
\hline & Distal & 13 & $43.3 \%$ & $18.5 \pm 4.5$ & \\
\hline
\end{tabular}

There were no statistical significant ( $\mathrm{p}$ value $>0.05$ ) correlation between COX-2 expression and age, diagnosis, grading, lymph nodes (L.N) and location in studied patients. There was statistically significant ( $p$-value < 0.05) correlation between COX-2 expression and sex and staging in studied patients (Table 3).

Table (3): Correlation between COX2 expression and age, sex, diagnosis, staging, grading, lymph nodes (L.N) and location

\begin{tabular}{|c|c|c|c|c|c|c|}
\hline \multicolumn{2}{|c|}{$\begin{array}{ll}\text { Carameters } & \text { COX2 expression } \\
\end{array}$} & \multicolumn{2}{|c|}{$\begin{array}{l}\text { Negative } \\
(n=7)\end{array}$} & \multicolumn{2}{|c|}{$\begin{array}{l}\text { Positive } \\
(\mathbf{n}=\mathbf{2 3})\end{array}$} & P-value \\
\hline \multirow{2}{*}{ Age } & $<50$ years & 5 & $71.4 \%$ & 18 & $78.3 \%$ & \multirow{2}{*}{0.708} \\
\hline & $>50$ years & 2 & $28.6 \%$ & 5 & $21.7 \%$ & \\
\hline \multirow{2}{*}{ Sex } & Male & 6 & $85.7 \%$ & 8 & $34.8 \%$ & \multirow{2}{*}{0.018} \\
\hline & Female & 1 & $14.3 \%$ & 15 & $65.2 \%$ & \\
\hline \multirow{2}{*}{ Diagnosis } & Adenocarcinoma & 3 & $42.9 \%$ & 16 & $69.6 \%$ & \multirow{2}{*}{0.199} \\
\hline & Other & 4 & $57.1 \%$ & 7 & $30.4 \%$ & \\
\hline \multirow{2}{*}{ Staging } & I + II & 5 & $71.4 \%$ & 6 & $26.1 \%$ & \multirow{2}{*}{0.029} \\
\hline & III & 2 & $28.6 \%$ & 17 & $73.9 \%$ & \\
\hline \multirow{2}{*}{ Grading } & Poor & 1 & $14.3 \%$ & 5 & $21.7 \%$ & \multirow{2}{*}{0.666} \\
\hline & Well + Moderate & 6 & $85.7 \%$ & 18 & $78.3 \%$ & \\
\hline \multirow{2}{*}{ Lymph nodes } & Negative & 2 & $28.6 \%$ & 6 & $26.1 \%$ & \multirow{2}{*}{0.896} \\
\hline & Positive & 5 & $71.4 \%$ & 17 & $73.9 \%$ & \\
\hline \multirow{2}{*}{ Location } & Proximal & 2 & $28.6 \%$ & 8 & $34.8 \%$ & \multirow{2}{*}{0.760} \\
\hline & Distal & 5 & $71.4 \%$ & 15 & $65.2 \%$ & \\
\hline
\end{tabular}




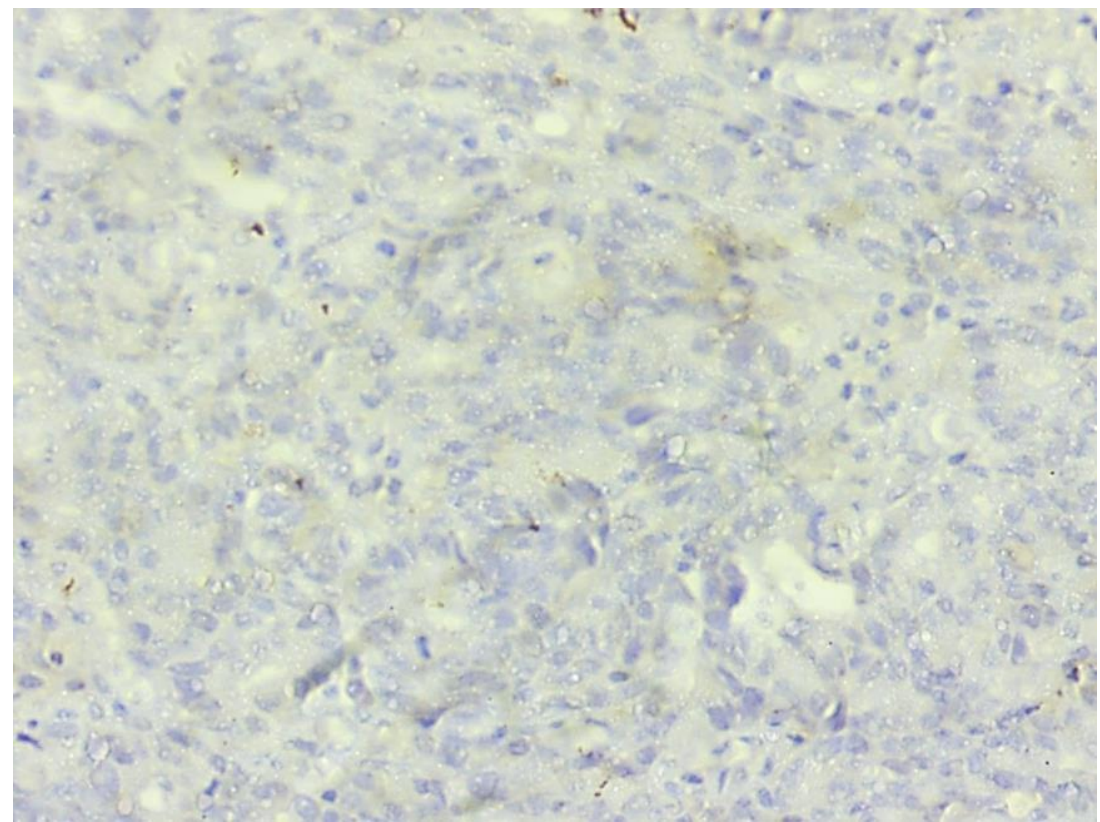

Figure (1): A case of moderately-differentiated adenocarcinoma (grade II), Negative for COX-2 (Hx. x100)

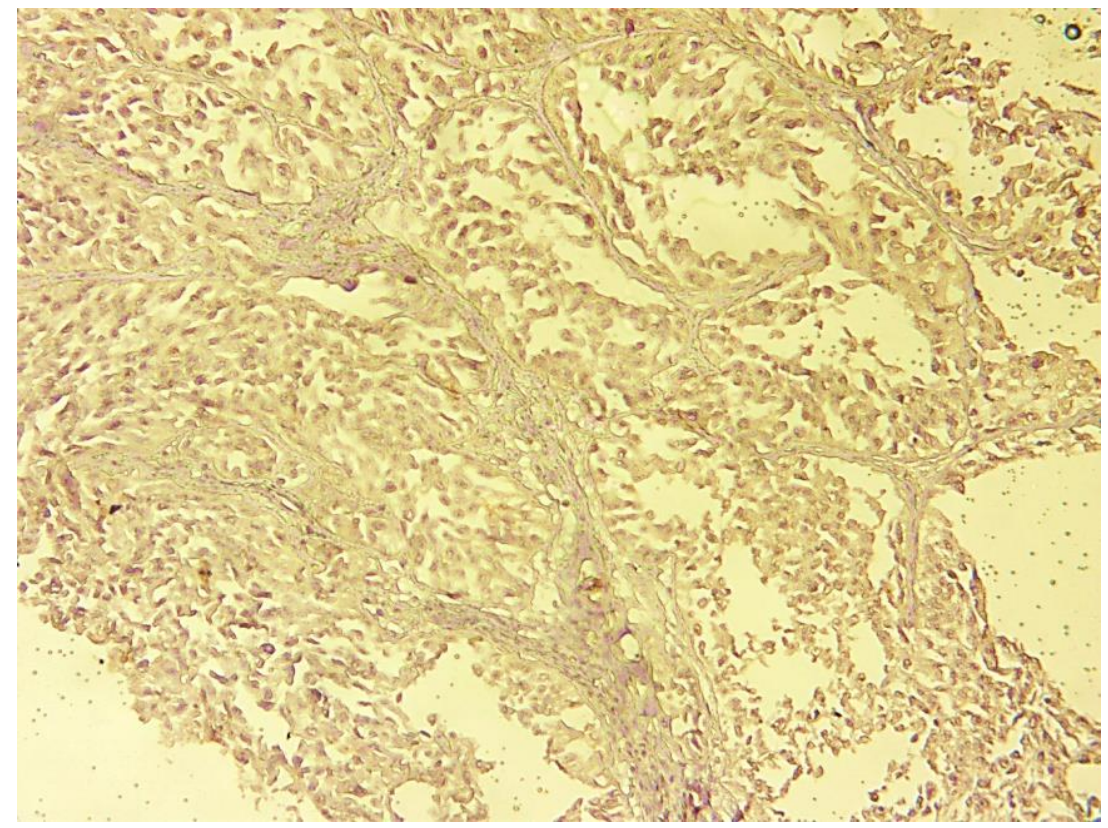

Figure (2): A case of poor-differentiated adenocarcinoma (High grade), showing weak cytoplasmic cox-2 expression (Hx. x200) 


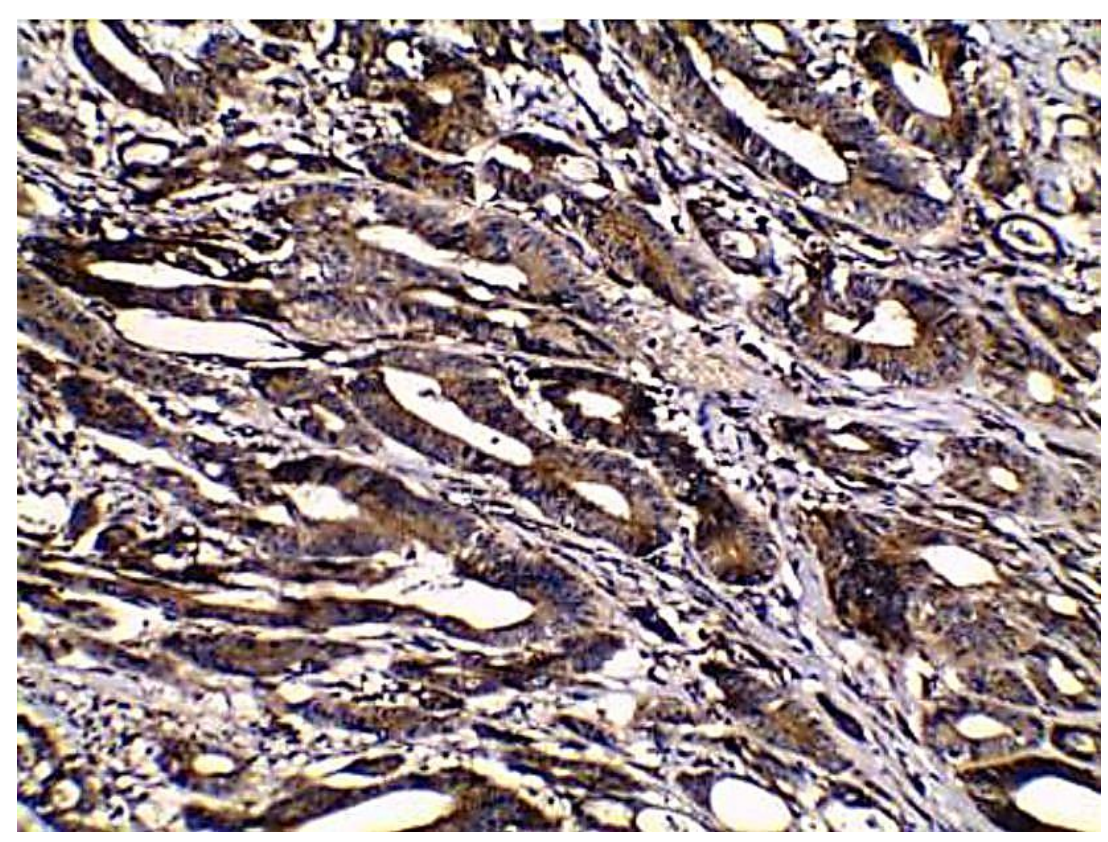

Figure (3): A case of moderately-differentiated adenocarcinoma (grade II), showing strong cytoplasmic COX-2 expression (Hx. X200)

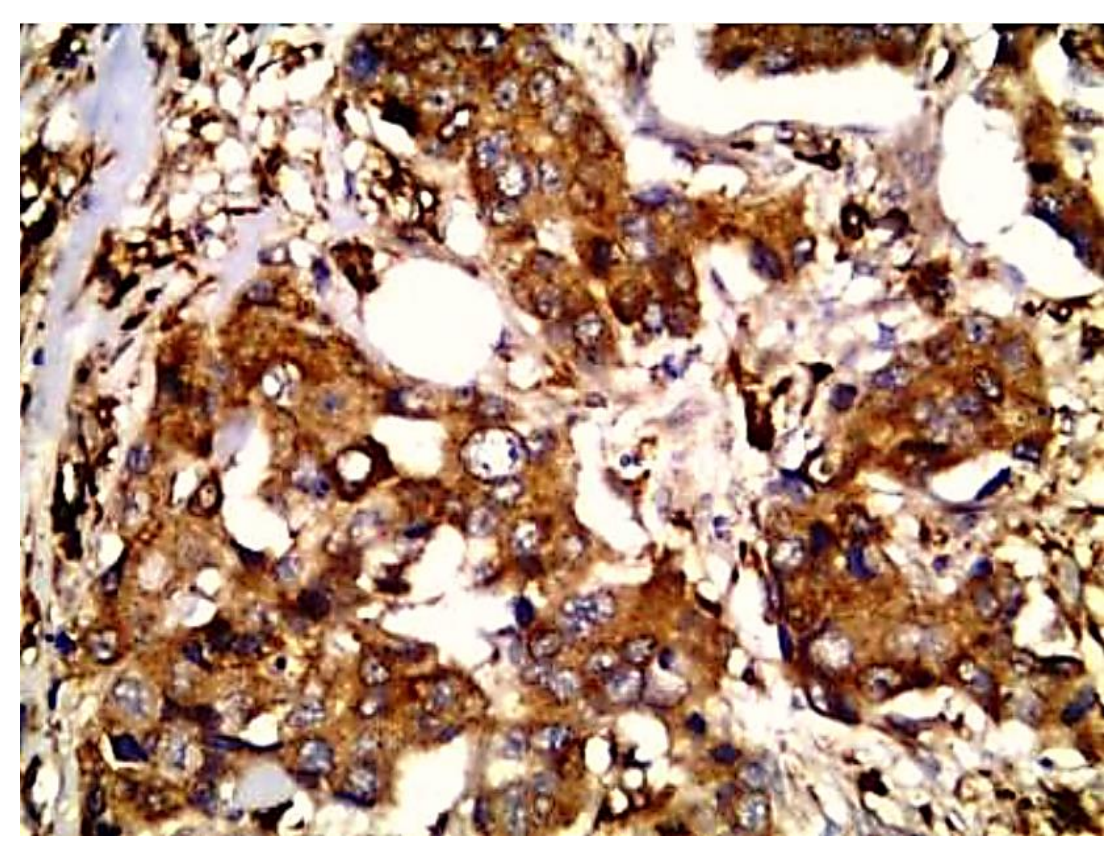

Figure (4): A case of poor-differentiated adenocarcinoma (High grade), showing moderate cytoplasmic cox-2 expression (Hx. x400). 


\section{DISCUSSION}

Collard et al. (2020) showed for the first time that knocking down BCL 3 expression suppressed cyclooxygenase 2 (COX 2)/prostaglandin E2 (PGE2) signalling in colorectal cancer cells, a pathway known to drive several of the hallmarks of cancer. RNAi mediated suppression of $\mathrm{BCL} 3$ expression decreased COX 2 expression in colorectal cancer cells both at the mRNA and protein level. Results suggest that targeting BCL 3 to suppress PGE2 synthesis may represent an alternative or complementary approach to using non-steroidal antiinflammatory drugs [(NSAIDs), which inhibit cyclooxygenase activity and suppress the conversion of arachidonic acid to prostaglandin], for prevention and/or recurrence in PGE2 driven tumorigenesis.

Arber et al. (2010), Bertagnolli et al. (2010) and Sheehan et al. (2010) studies suggested that there is an important role of COX-2 over-expression in colorectal carcinogenesis. COX-2 was first demonstrated to be increased in colorectal cancer by Eberhart et al. (2010) and, thereafter, numerous studies by Soumaoro et al. (2010), Yamauchi et al. (2010) and Xiong et al. (2010) had shown inconstant expression levels of COX-2 in colorectal cancer. As regards COX-2 expression, it was positive in $76.7 \%$ and negative in 23.3\%. Also Mahmoud et al. (2014) revealed that COX-2 is positive in most cases of colorectal carcinoma. $W u$ and Sun (2015) showed that positive rates of COX-2 expression in colorectal cancer were $77.97 \%$. Albasri et al. (2018) observed that cyclooxygenase- 2 overexpression was observed in $84.6 \%$ of
CRC cases. Tupá et al. (2019) showed that COX-2 protein was expressed in 84.7\%. Negi et al. (2019) found that quantitative relative expression of COX-2 mRNA was observed to be significantly higher in colorectal cancer tissues as compared to adjacent normal colon tissues.

Our results revealed that COX-2 expression had no significant correlation with age, diagnosis, location, grading and lymph node affection. Those previous findings were in consistence with $\mathrm{Al}$ Maghrabi et al. (2012), Kazem et al. (2014), Wu and Sun (2015) and Albasri et al. (2018). Mahmoud et al. (2014) study showed no association between COX-2 expression and the clinicopathological features shown, as regards tumor size, tumor location, gross picture, histological type, venous or Perineural invasion, lymph node metastasis and Dukes' classification. Venkatachala and Rajendran (2017) reported no significant relationship between elevated COX-2 expression and clinicopathological features including tumor location, age, TNM stage, histopathological classification, lymph node metastasis, and histopathological differentiation which were similar to the study of Negi et al. (2019).

Kazem et al. (2014) had reported statistically significant relationships between pathological grade and COX-2 positivity scores. However, those previous results were in contrast to the study of $W u$ and Sun (2015). Venkatachala and Rajendran (2017) reported that COX-2 overexpression was related to increasing stage and depth of invasion. On the other hand, our results revealed significant 
positive correlation of $\mathrm{COX}-2$ expression with sex and with staging. Those previous results were in consistence with Albasri et al. (2018) who revealed COX-2 overexpression highly significant correlations with advanced stages but according to gender there results revealed no significant correlations between COX-2 over-expression and gender. Negi et al. (2019) stated that female CRC patients showed significantly higher expression of COX-2 mRNA vis-a-vis male colorectal cancer patients. Tupá et al. (2019) showed that COX-2 expression was only significantly correlated with the tumor stage.

As regards COX-2 expression intensity, it was weak in $17.4 \%$, moderate in $43.5 \%$ and strong in $39.1 \%$. Tupá et al. (2019) stated that COX-2 protein immunoreaction intensity was predominantly strong $(47.8 \%)$.

Our results revealed that COX-2 expression intensity had no significant correlation with age, diagnosis, location, grading and lymph node affection. On the other hand, our results revealed significant positive correlation of COX-2 expression with sex and with staging.

Taken together, these findings suggested that COX-2 has synergistic effect by affection on staging in colorectal cancer. COX-2 expression had no significant correlation with age, or tumor location. Also, CoX-2 protein may represent dependent prognostic factor of CRC. However, further controlled and randomized studies are needed to validate our findings in a larger cohort of patients.

\section{CONCLUSION}

COX-2 expression was found to have a significant association with gender and was assumed to play an important role in colorectal carcinogenesis. Further, these findings supported the view that overexpression of $\mathrm{COX}-2$ in colorectal carcinoma suggests its role as a potential biomarker for diagnosis of colorectal cancer with an emphasis on development of COX-2 inhibitors as potential promising chemo-preventive drugs for colorectal cancer.

\section{REFERENCES}

1. Albasri AM, Elkablawy MA, Hussainy AS and Alhujaily A. (2018): Impact of cyclooxygenase-2 over-expression on the prognosis of colorectal cancer patients. Saudi Med J., 39(8): 773-780.

2. Al-Maghrabi J, Buhmeida A, Emam E and Tarakji B. (2012): Cyclooxygenase-2 expression as a predictor of outcome in colorectal carcinoma. World J Gastroenterol., 18:1793-9.

3. Arber N, Eagle CJ and Spicak J (2010): Celecoxib for the prevention of colorectal adenomatous polyps. N Engl J Med., 355:885-5.

4. Bertagnolli MM, Eagle CJ, Zauber AG, Redston M, Solomon SD and Kim K. (2010): APC Study Investigators: Celecoxib for the prevention of sporadic colorectal adenomas. N Engl J Med., 355:873-84.

5. Collard TJ, Fallatah HM and Greenhough A. (2020): BCL 3 promotes cyclooxygenase 2/prostaglandin E2 signalling in colorectal cancer. International Journal of Oncology, 56(5):1304-1313.

6. Eberhart CE, Coffey RJ and Radhika A. (2010): Up-regulation of cyclooxygenase 2 gene expression in human colorectal adenomas and adenocarcinomas. Gastroenterology, 107:1183-1188.

7. Hamilton SR, Bosman FT and Boffetta P. (2011): Tumors of the colon and rectum. In: 
Bosman FT, Carneiro F, Hruban RH (eds): WHO Classification of Tumors of the Digestive System (ed4). Lyon, France: International Agency for Research on Cancer. Pp. 134-146.

8. Kazem A, El Sayed $K$ and El Kerm Y (2014): Prognostic significance of $\mathrm{COX}-2$ and b-catenin in colorectal carcinoma. Alexandria Journal of Medicine, 50:211-220.

9. Lim SC, Lee TB, Choi CH and Min Y. (2010): Expression of cyclooxygenase-2 and its relationship to p53 accumulation in colorectal cancers. Yonsei Med J., 48:495501.

10. Liu B, Qu $L$ and Yan $S$ (2015): Cyclooxygenase-2 promotes tumor growth and suppresses tumor immunity. Cancer Cell Int., 15:106-110.

11. Mahfouz EM, Sadek RR, Abdel-Latief WM, Mosallem FA and Hassan EE. (2014): The role of dietar and lifestyle factors in the development of colorectal cancer: Case control study in Minia, Egypt. Cent Eur J Public Health, 22 (4): 215-222.

12. Mahmoud AS, Umair A, Azzeghaiby $\mathrm{SN}$, Alqahtani FH, Hanouneh $S$ and Tarakji B. (2014): Expression of Cyclooxygenase-2 (COX-2) in Colorectal Adenocarcinoma: an Immunohistochemical and Histopathological Study. Asian Pac J Cancer Prev., 15 (16): 6787-6790.

13. Negi RR, Rana SV, Gupta V and Dhawan D. (2019): Over-Expression of Cyclooxygenase-2 in Colorectal Cancer Patients. Asian Pac J Cancer Prev., 20(6): 1675-1681.

14. Perisa MM, Sarcevic $B$ and Troselj KG. (2017): Expression of $n m 23-\mathrm{H} 1$ and $\mathrm{COX}-2$ in thyroid papillary carcinoma andmicrocarcinoma. Oncology Letters, 13(5): 3547-3555.

15. Raskov H, Pommergaard HC and Burcharth J. (2014): Colorectal carcinogenesis--update and perspectives. World J Gastroenterol., 20: 18151-18164.
16. Sheehan KM, Sheahan $K$ and O'Donoghue DP. (2010): The relationship between cyclooxygenase 2 expression and colorectal cancer. JAMA, 282:1254-7.

17. Sideris $M$ and Papagrigoriadis S. (2014): Molecular biomarkers and classification models in the evaluation of the prognosis of colorectal cancer. Anticancer Res., 34: 20612068.

18. Soumaoro LT, Uetake $H$, Higuchi $T$ and Ghoraba H. (2010): Cyclooxygenase-2 expression: A significant prognostic indicator for patients with colorectal cancer. Clin Cancer Res., 10:8465-1.

19. Tupá $V$, Drahošová $S$, Grendár $M$ and Adamkov M. (2019): Expression and association of carbonic anhydrase IX and cyclooxygenase- 2 in colorectal cancer. Pathol Res Pract., 215(4):705-711.

20. Venkatachala $S$ and Rajendran M. (2017): Correlation of COX- 2 expression in colorectal carcinoma with clinicopathological features. Turk Patoloji Derg., 33:228-4.

21. Wang $D$ and Dubois RN. (2010): Eicosanoids and cancer. Nat Rev Cancer, 10:181-193.

22. Wu QB and Sun GP. (2015): Expression of COX-2 and HER-2 in colorectal cancer and their correlation. World J Gastroenterol., 21(20): 6206-6214.

23. Xiong B, Sun TJ, Hu WD and Cheng F. (2010): Expression of cyclooxygenase- 2 in colorectal cancer and its clinical significance. World J Gastroenterol., 11:1105-8.

24. Yamauchi T, Watanabe $M$, Kubota $T$, Hasegawa H, Ishii Y, Endo T, Kabeshima Y, Yorozuya K, Yamamoto K, Mukai M. (2010): Cyclooxygenase-2 expression as a new marker for patients with colorectal cancer. Dis Colon Rectum, 45:98-103. 
در اسة هيستوكيميائية مناعية لتعبير كوكس-2 في سرطان القولون و المستقبم

مصباح فكري محمد السيد, سعيد أبو الخير محمد, ناصر عبد النبي عمر قسم الباثولوجيا العامة, كلية الطب، جامعة الازهر

E-mail: mesbah.fekry@gmail.com

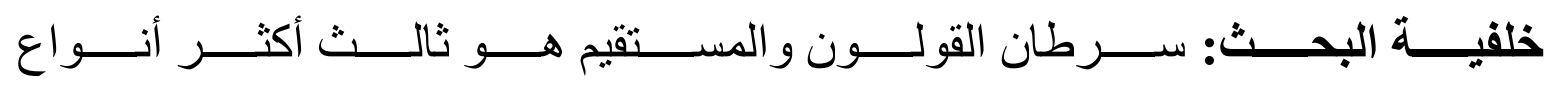

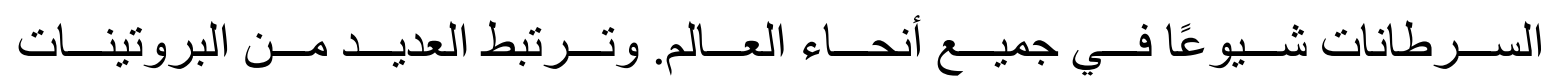

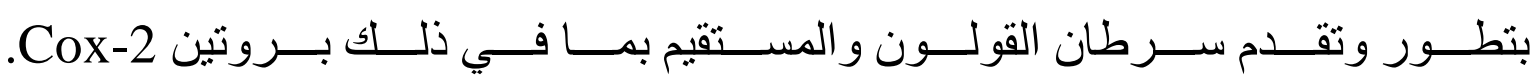

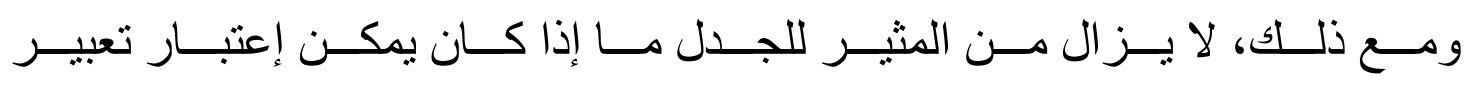

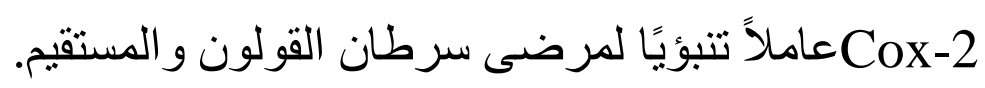

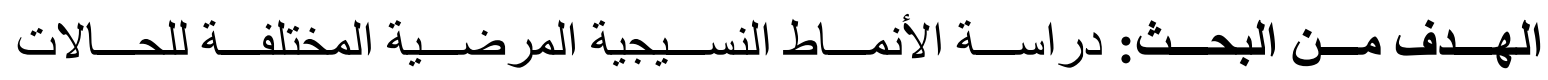

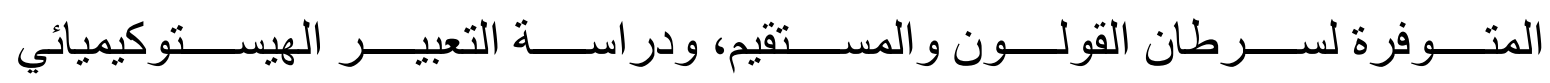

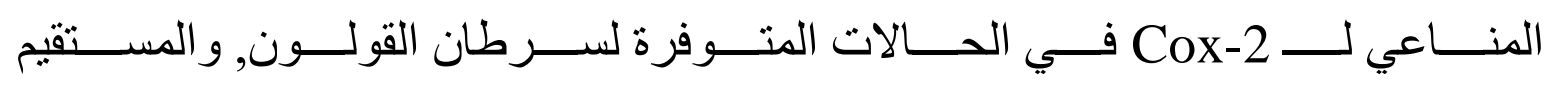

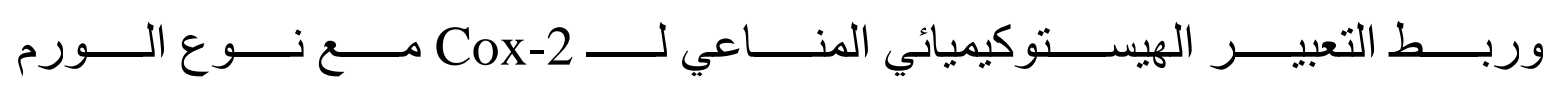

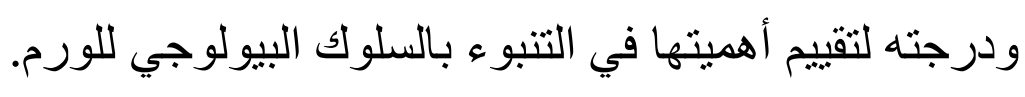

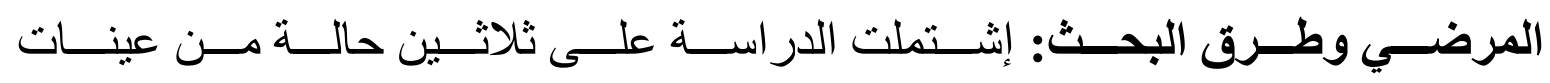

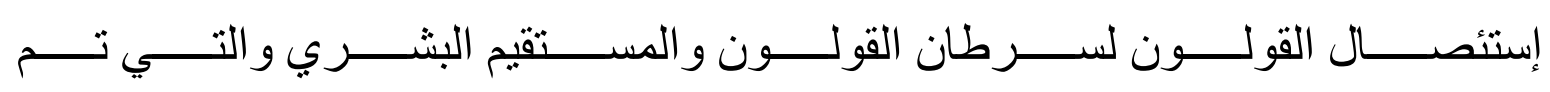

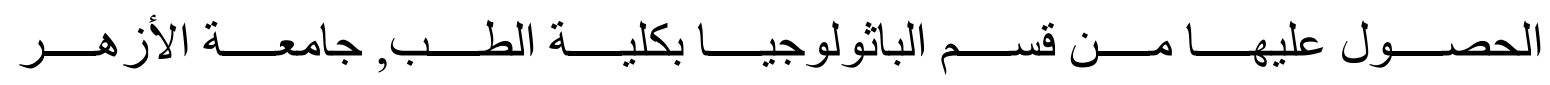

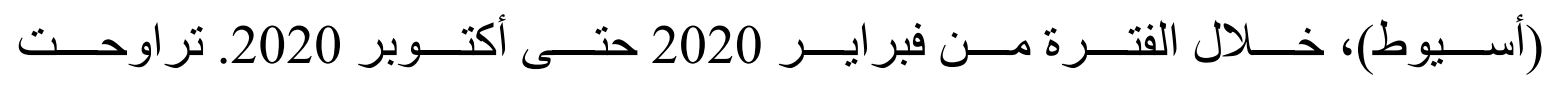

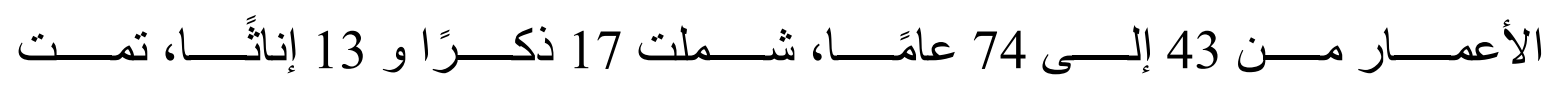

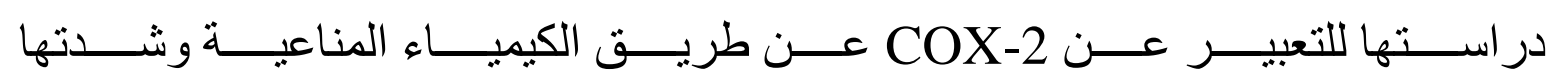

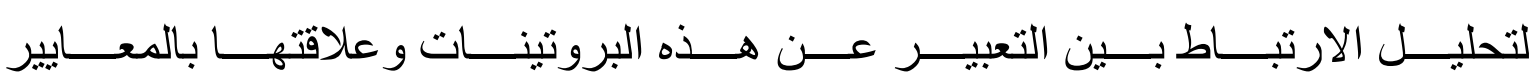

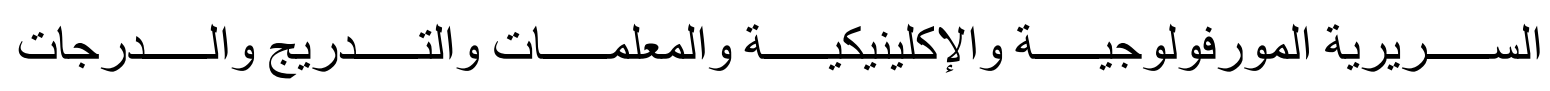
و العقدة الليمفاوية والموقع. 


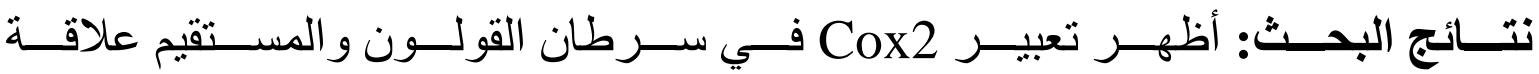

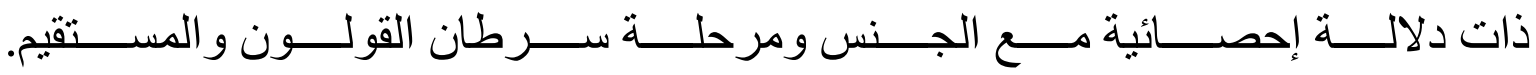

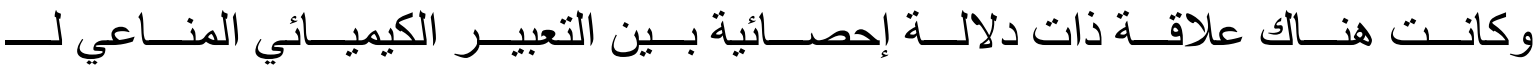
Cox-2 في سرطان القولون و المستقيم.

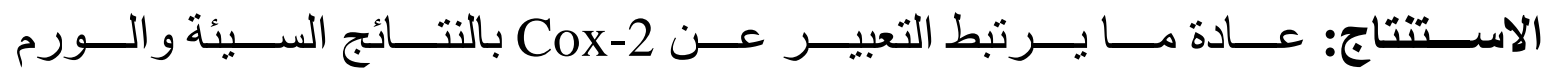
الخبيث في سرطان القولون و المستقيم. الكلمات الدالة: Cox2، سرطان القولون و المستقيم. 